\title{
Homelikeness and health: an introduction to the theme
}

\author{
Stephen Tyreman
}

Published online: 23 February 2011

(C) Springer Science+Business Media B.V. 2011

To claim that health and illness are fundamental aspects of human life is so obviously true it is hardly worth stating, yet, Illich (1976) controversially opined in the 1970s that health and illness had been 'expropriated' from many peoples' lives by the healthcare industry. He argued that the 'medicalization' of life was more harmful than beneficial and that society should resist it.

Little has changed since then to ameliorate Illich's concerns. Two of the most significant events in any person's life-birth and death-have become more medicalised and largely removed from the care of the local community, so that today in Western society the majority of people are born and die in medicalised care. Less than $1 \%$ of babies are born at home in the USA (MacDormanet al. 2010) and under 3\% in the UK, which is a dramatic drop from $85 \%$ in 1927. (Nove et al. 2008) In the USA $75 \%$ of people die either in hospital or a nursing home despite the popular preference to die at home. (Cassel and Demel 2001).

There are good reasons for many of these changes and one can point to corresponding improvements in infant survival rates and life expectancy, though whether they are causally related is less clear. Nevertheless there is a lack of congruity between an individual's personal, subjective experience of health and illness as the ever-present backdrop to their life and the impersonal, objective way in which it is often explained in medical texts and sometimes managed in care institutions. Institutionalizing care by taking people out of their homes and into hospitals and nursing homes places them in unfamiliar surroundings and

\footnotetext{
S. Tyreman $(\square)$

British School of Osteopathy, 275 Borough High Street,

London SE1 1JE, UK

e-mail: S.Tyreman@bso.ac.uk
}

cultures that have their own languages, practices and values. The resulting alienation can be felt at many levels: patients may miss the familiarity of their physical environment; find it hard to understand the illness; fail to recognise the behaviour of their own bodies or to find personal meaning in the experience. The illness and very often the care and treatment they receive, may leave them feeling alienated within their life and in a body and a location they no longer recognise or feel at home in.

Appreciating the demarcation between the internal and external and protecting the internal body from unwelcome external invasion is a theme that is echoed in the anthropological literature. Cieraad (1999) sees a clear relationship between the way the domestic space of the home is designed and organised, and the development of personal identity. She highlights the traditional role of Dutch women to control 'the liminal zone between the domestic space of the home and public space of the street.' (ibid. p. 4) Hygiene, health and cleanliness are internal private matters carried out in the home and away from the street, paralleling the clear differences between internal and external experiences of health and illness.

It also reminds us that physical removal from the usual place of dwelling at the most vulnerable times of life may not only alienate in a psychological sense, but lead to a more profound change in the sense of embodiment and loss of identity. We all hold "attachments" to places at various times in our lives. In different ways these become extensions of our sense of self, popularly described as our 'roots'.

The challenge that results from the increasing gulf between the internal personal experience of illness and the external medicalization of it is not about deciding which is right and which wrong, as Illich was suggesting, but of knowing how to integrate different stories about life, health 
and illness. The stories people tell of their health, the stories health care professionals tell and the stories society/ politicians/historians tell are more than different accounts of the same story; they are often like different events occurring in the same place and time.

The idea of different narratives is intrinsic to the "is medicine an art or a science?" debate. The story of a woman with a persistent cough that disturbs her sleep and causes incontinence is different from the story of a malignant tumour that grows in the lung. Support and care for the person, entails a different strategy from that of dealing with the disease. We know the stories are intimately connected, but we do not yet have a coherent way of bringing them together. Narrative-based care uses the idea of a shared narrative to integrate them, but for the moment it lacks a coherent conceptual and theoretical foundation.

Toulmin (1993), in his paper on knowledge and art in medicine argues that taking the patient's history is the central feature that defines the physician. "To understand your patient is to understand his "history" - to understand who he is and how he now perceives himself to be' (ibid. p. 240). Illness is not only physiological and pathological deviation; in a fundamental way the person's sense of being is challenged and threatened by illness. Medicine's epistemological task of identifying biological abnormalities only goes so far in explaining the existential nature of illness, and fails completely to overcome the alienation it helped to generate. Further hermeneutical work is required to contextualise the illness experience in the patient's life and make it meaningful again. Acknowledging the patient's history is certainly part of that work, but it is not enough.

In his classic work Being and Time, Heidegger (1962) points to other aspects of being human, particularly to what he terms 'Dasein', the phenomenon of human-being. The Swedish philosopher, Svenaeus (1999) has taken Heidegger's work in order to develop 'a philosophy of medical practice'. This follows the phenomenological tradition established by Husserl, Merleau-Ponty and Heidegger and taps a rich vein to explore the broad human experience of health/illness in relation to being. The sense of alienation and homelessness that accompanies and defines illness, is a central feature of Svenaeus's work.

In this set of five essays different aspects of this central theme are explored.

In the first paper, Dekkers (2011) focuses on home and dwelling and their place in our experience of embodiment, health and illness. He reviews Heidegger, Bollnow, Bachelard and Levinas's understanding of home, house and dwelling, and points out that although there are significant differences between them, they agree on the basic idea that 'being human is to dwell'. The physical world environs us and being at home is a particularly significant form of environing. He uses the example of dementia and points out that for elderly people home can play a critical part in maintaining their identity. The home becomes the focus for the Heideggerian notions of being here (at home), being there (in a nursing home or hospital), being out (visiting, shopping etc.) and keeping out (resisting threats that might invade). Dekkers highlights a key question in dementia, which is whether it is possible to lose the capacity to dwell and what the implications of that might be.

Tyreman (2011) calls on the medium of literature and poetry to further explicate the meaning of illness. His claim is that literature and particularly poetry are explanatory media in their own right, using story, mood and imagery. They enhance our ability to engage with the world by enlarging our existential understanding. What results is not just a story about someone experiencing illness or health, but an ontological phenomenology that is whole and complete in itself. The short story, The Country of the Blind by H.G. Wells, and the poem Danse Russe by William Carlos Williams, portray key ideas about health and illness with an immediacy that Heidegger would later develop in his work. A theme that is common to both pieces is the idea that physical engagement and embodiment through the 'tools' of human senses plus the ability to move, is fundamental to Dasein. Human action is therefore a determinant rather than a consequence of health.

Edgar (2011) questions whether Svenaeus's narrow emphasis on health, illness and disease as personal experiences, is justified. He argues that there is also a rich sociological tradition that understands illness in relation to social alienation rather than only through the ontological condition of Dasein. Employing the writings of authors such as Camus, Mann and McCuller, he explores the modernist understanding of the human social condition as the 'tragic community of strangers'. Thus, alienation and the uncanny are central to human life rather than merely the existential effect of illness. Illness is not a intervallic alien state, but something that 'always already lies within a complex web of interpretations, metaphors and allusions.' Illness is therefore a 'socially and culturally mediated (challenge) that demands political as well as individual therapeutic intervention.'

The suggestion that Svenaeus's account of illness as unhome-likeness could be further developed is taken up in Ahlzén's paper (2011). Writing from his perspective as a medical General Practitioner, he is enthusiastic about the need to 'excavate the meaning structures of illness', but is concerned about the difficulty of translating a sophisticated philosophical analysis into useful clinical practice. In particular, Ahlzén is concerned that for non-phenomenologists, the concepts of home and home-likeness have a meaning that is different from that posited by Heidegger. 
Being at home is either literal or metaphorical for most people; the complex notion of 'homelike', understood in terms of phenomenological hermeneutics, has little meaning or relevance without further illumination.

In the final paper Fredrik Svenaeus (2011) reiterates his proposal that health is homelike and illness unhomelike being-in-the-world by arguing that the underlying meaning structure of the illness experience is best explained in terms of the relationship between 'otherness' (as alienation) and meaningfulness. The claim is that disease (in line with Heidegger's example of a catastrophe in nature) is an event that breaks in on us and destroys us meaninglessly. Meaninglessness has a temporal dimension: instead of being a meaningful whole, past and future become separated from the present. This separation, Svenaeus argues, is best understood metaphorically through stories that help explain our life experience, and specifically, the chaotic sense of alienation and unhomelike-ness that illness brings. This necessitates a retelling of the past and future narrative. Although 'life is a story' is metaphorical in the sense that life isn't really a story only (in important ways) like a story, it is not metaphorical in the sense that stories explain life experiences ontologically.

At the same time as sociologists such as Illich were highlighting problems in Western medicine, philosophers of healthcare in the 1970s and 1980s were challenging prevailing biological explanations of human health, illness and disease. As a result, the simplistic idea that illness and disease can be understood in purely biological terms has been overturned, but it has not yet been replaced by a credible alternative basis for clinical practice. These five papers and the basic themes they explore offer such an alternative by highlighting the human experience of health and illness as embodied dwelling in the world, phenomena with physical, psychological, social and cultural elements.

\section{References}

Ahlzén, R. 2011. Illness as unhomelike being-in-the-world? Phenomenology and medical practice. Medicine, Health Care and Philosophy. This Issue.

Cassel, C.K., and B. Demel. 2001. Remembering death: public policy in the USA. Journal of the Royal Society of Medicine 94: 433-436.

Cieraad, I. (ed.). 1999. At home: an anthropology of domestic space. New York: Syracuse University Press.

Dekkers, W. 2011. Dwelling, house and home: towards a home-led perspective on dementia care. Medicine, Health Care and Philosophy. This Issue.

Edgar, A. 2011. The uncanny, alienation and strangeness: the entwining of political and medical metaphor. Medicine, Health Care and Philosophy. This Issue.

Heidegger, M. 1962. Being and time (trans: Macquarrie, J. and Robinson, E.). Oxford: Blackwell Publishing.

Illich, I. 1976. Limits to medicine. Medical nemesis: the expropriation of health. London: Penguin.

MacDorman, M., F. Menacker, and E. Declercq. 2010. Trends, characteristics of home, other out-of-hospital births in the United States, 1990-2006. National vital statistics reports National Center for Health Statistics 58(11): 1-14.

Nove, A., A., Berrington, and Z., Matthews. 2008. Home births in the UK 1955-2006. Newport: HMSO Retrieved from http://www. statistics.gov.uk/statbase/Product.asp?vlnk=6303.

Svenaeus, F. 1999. The hermeneutics of medicine and the phenomenology of health. Linköping: The Tema Institute, Linköping University.

Svenaeus, F. 2011. Illness as unhomelike being-in-the-world: Heidegger and the phenomenology of medicine. Medicine, Health Care and Philosophy. This Issue.

Toulmin, S. 1993. Knowledge and art in the practice of medicine: clinical judgment and historical reconstruction. In Science, technology, and the art of medicine, vol. 44, ed. C. Delkekamp-Hayes, and M.A. Gardell Cutter, 231-249. Dordrecht: Kluwer Academic Publishers.

Tyreman, S. 2011. The happy genius of my household: phenomenological and poetic journeys into health and illness. Medicine, Health Care and Philosophy. This Issue. 